\title{
fenomenología
}

\section{Aunque te sientas inútil... Relato de una experiencia}

\section{Even though you may feel useless... Story about an experience}

\section{Mesmo que você pode se sentir inútil... Relato de uma experiência}

\author{
Raquel A. Díaz Alonsoํㅜ David Palacios Martínez ${ }^{2}$ \\ ${ }^{1}$ Diplomada Universitaria en Enfermería. Servicio de Medicina Interna. \\ Hospital Universitario de Fuenlabrada. Fuenlabrada, Madrid, España. \\ ${ }^{2}$ Médico de Familia. Servicio Madrileño de Salud - SERMAS. Dirección Asistencial Sur de Madrid. \\ C.S. San Blas (Parla, Madrid, España).
}

Cómo citar este artículo en edición digital: Díaz Alonso, R.A. y Palacios Martínez, D. (2014) Aunque te sientas inútil... Relato de una experiencia. Cultura de los Cuidados (Edición digital) 18, 39. Disponible en: http://dx.doi.org/10.7184/cuid.2014.39.02>

Correspondencia: Raquel Asunción Díaz Alonso. C/ Nazaret, No6, Portal 2, 2º. Parla C.P. 28980. Madrid

E-mail: raquelda_parla@hotmail.com

Recibido: 10/12/2013; Aceptado: 14/03/201

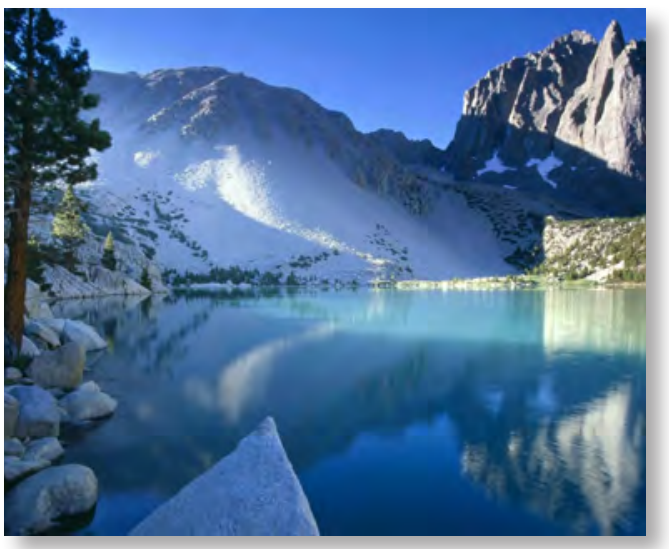

ABSTRACT

Work in the health field can be very demanding at the affective level. The emotional component in the personal relationship affects all those involved: patients, families and professionals. It can lead us to feel upset, as in this story, when we believe that our actions have proved futile. On numerous occasions we do not come to know our real impact on the lives of patients. All health professionals have some experience that moves us. This is mine.

Key words: holistic nursing; nurse-patients relation; philosophy, nursing.

\section{RESUMO}

Trabalho no campo da saúde pode ser muito exigente a nível afetivo. $\mathrm{O}$ componente emocional no relacionamento pessoal afeta todos os envolvidos: pacientes, familiares e profissionais. Ela pode levar-nos sentir chateada, como esta história, quando acreditamos que nossas ações têm foram infrutíferos. Em várias ocasiões não viemos conhecer nosso verdadeiro impacto na vida dos pacientes. Todos os profissionais de saúde têm alguma experiência que nos move. Isto é meu.

Palavras-chave: enfermagem holística; relações enfermeiro-paciente; filosofía em enfermagem.

\section{RESUMEN}

El trabajo en el ámbito sanitario puede resultar muy exigente a nivel afectivo. El componente emotivo en la relación personal influye en todos los implicados: pacientes, familiares y profesionales. Puede llevarnos a sentir malestar, como en este relato, cuando creemos que nuestras acciones han resultado fútiles. En 
numerosas ocasiones no llegamos a conocer nuestro verdadero impacto sobre las vidas de los pacientes. Todos los profesionales sanitarios tenemos alguna experiencia que nos conmueve. Ésta es la mía.

Palabras clave: enfermería holística; relaciones enfermero-paciente; ética en enfermería; filosofía en enfermería.

Fue un día cualquiera. Yo era una joven estudiante de enfermería. Durante unas prácticas en la Unidad de Cuidados Intensivos, llegó una paciente con pronóstico grave. En coma inducido farmacológicamente e intubada. Con los monitores avisando cada poco tiempo de que la vida se le escapaba. Un gran equipo se encargaba de intentar evitarlo. Yo me sentía, día tras día, inútil e impotente. Mis conocimientos y habilidades, evidentemente, ni se acercaban a los de mis tutores. Por ello, me dedicaba en los escasos ratos libres a estar con aquella paciente. A pesar de su inconsciencia, yo le daba la mano. Y le hablaba. Le hablaba mucho. Le contaba si el día estaba lluvioso o con sol. Le decía que el horario de visitas empezaría pronto. Que poco a poco iba mejorando, y estábamos todos muy contentos de que así fuera. Tenía la sensación de que me escuchaba, a pesar de estar inconsciente, sedada. Cuanto más le hablaba, más relajado me parecía su rostro. A veces, ya en mi casa, pensaba que todo eran imaginaciones mías, que sólo estaba tratando de sentirme útil.

Unas semanas después, mis prácticas acabaron. Había aprendido muchísimo, gracias a que todo el personal del servicio se había esforzado en integrar a los alumnos en el equipo y en darnos una sólida base. Pero era consciente de que aún me faltaban muchas cosas por aprender. El día que le dije adiós, aquella paciente aún estaba sedada. Ya nunca sabría qué había sido de ella, pero confiaba en que seguiría mejorando.

Cuatro años después, otro día cualquiera, estaba ya trabajando como enfermera en una planta. Una ciudad y una vida diferentes. Al empezar mi ronda de aquel turno, tensiómetro en mano, entré en una habitación en la que habían ingresado dos mujeres en turnos anteriores. Sus nombres no me sonaban; sus caras, tampoco. Al saludar a la primera, su rostro se iluminó. Sus labios temblaron durante un segundo, hasta dar paso a una gran sonrisa. Brillantes lágrimas de emoción cayeron de unos ojos que yo nunca había visto abiertos. "Reconozco tu voz", me dijo entonces. Fue la primera frase de una larga conversación. Conversación en la que me contó que, cuando había estado tan enferma, le calmaban las cosas que yo le contaba. Entre brumas y pesadillas. Una sencilla frase que, aún hoy, cuando recuerdo esta experiencia, me eriza la piel y me llena los ojos de lágrimas de emoción.

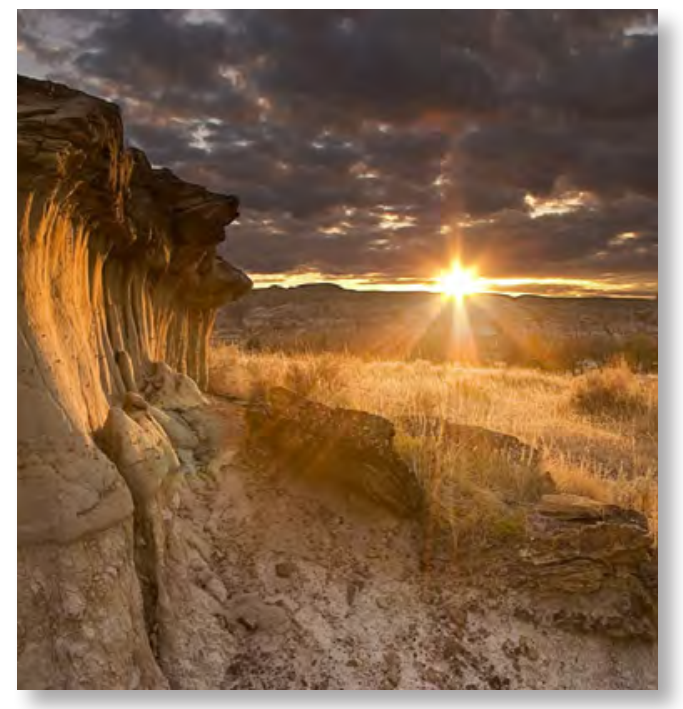

